ISSN = 1980-993X - doi:10.4136/1980-993X
www.ambi-agua.net
E-mail: ambi-agua@agro.unitau.br
Tel.: (12) 3625-4212

\title{
Determinação de áreas prioritárias para o restabelecimento da cobertura florestal, apoiada no uso de geotecnologias
}

\author{
(http://dx.doi.org/10.4136/ambi-agua.964) \\ Celso de Souza Catelani ${ }^{1}$; Getulio Teixeira Batista ${ }^{2}$; \\ Marcelo dos Santos Targa ${ }^{2}$; Nelson Wellausen Dias ${ }^{3}$ \\ ${ }^{1}$ Programa de pós-graduação em Engenharia Mecânica, UNESP-FEG \\ e-mail: cscatelani@gmail.com, \\ ${ }^{2}$ Programa de pós-graduação em Ciências Ambientais da Universidade de Taubaté (PPGCA) \\ e-mails: getulio@agro.unitau.br,mtarga@unitau.br, \\ ${ }^{3}$ Fundação Instituto Brasileiro de Geografia e Estatística, Diretoria de Geociências \\ e-mail: nwdias@gmail.com
}

\section{RESUMO}

A determinação de áreas prioritárias para o restabelecimento da cobertura florestal nativa em bacias hidrográficas se constitui numa necessidade diretamente associada à probabilidade de sucesso efetivo na recuperação e na maximização dos recursos necessários. No entanto, para atender a essa finalidade, a complexidade no tratamento e o volume de dados ambientais espacializados necessários requerem um aparato tecnológico capaz de processar dados de apoio à análise multicriterial como ferramenta de suporte à decisão, no estado da arte das geotecnologias aplicáveis. Nesse contexto, o presente trabalho desenvolvido para uma área de $476 \mathrm{~km}^{2}$ correspondente à área da bacia hidrográfica do rio Una, no município de Taubaté, SP, baseou-se em uma análise multicriterial usando classificação contínua e na técnica de comparação pareada AHP (Analytical Hierarchy Process), incorporados ao SIG completo denominado SPRING (Sistema de Processamento de Informações Georreferenciadas), para a geração de um mapa de áreas prioritárias para o restabelecimento da cobertura florestal nativa na bacia. Os resultados obtidos com base na análise dos fatores: valor da terra nua; distância de fragmentos; classes de capacidade de uso do solo; áreas de preservação permanente (APPs); dentre outros, revelaram uma grande área, correspondente a 26,6\% da área da bacia, classificada como "Prioridade Extrema". Isso indica a necessidade imediata de recuperação ambiental da bacia uma vez que ela é manancial para o abastecimento de Taubaté, SP. Os resultados permitem de forma prática subsidiar a tomada de decisão na alocação de recursos e projetos dessa natureza nessas áreas prioritárias.

Palavras-chave: floresta nativa, geotecnologia, bacia hidrográfica, AHP.

\section{Determination of priority areas for the re-establishment of forest cover, based on the use of geotechnologies}

\begin{abstract}
The determination of priority areas for the re-establishment of forest cover in watersheds is directly associated to the probability of effective success of restoration processes. However, considering the complexity of the analysis and the large amount of spatial data necessary to accomplish that purpose, state of the art technological tools capable of processing multicriteria analysis to support decision making are necessary. Thus, the current work developed for an area of $476 \mathrm{~km}^{2}$ corresponding to the Una river watershed in the municipal district of
\end{abstract}


Taubaté, SP, used a multi-criteria analysis based on the continuous classification and on Analytical Hierarchy Process (AHP) paired comparisons techniques, available in the complete GIS package named SPRING (Georeferenced Information Processing System) for generating a map of priority areas for the re-establishment of forest cover in that watershed. Results revealed a large area $(26.6 \%$ of the entire watershed) falling in the "Extreme Priority" class for forest cover re-establishment, what indicates the urgent need of environmental recovery of this basin considering that it is used for Taubaté city water supply. Results from this research support the decision making for resource optimization applied to priority areas in an operational way.

Keywords: forest cover, geotechnology, watershed, AHP.

\section{INTRODUÇÃO}

A legislação ambiental brasileira, no que se refere à conservação de maciços florestais e à determinação de áreas de preservação permanente (APP), em especial o Código Florestal (Lei 4771/1965), recentemente revogada pela Lei $\mathrm{N}^{\circ}$ 12.651, de 25 de maio de 2012 (Brasil, 1965, 2012), traz em seu texto condições legais que se aplicadas seriam fundamentais para a preservação da cobertura vegetal florestal e para o estabelecimento de corredores ecológicos importantes para permitir o fluxo gênico e promover a melhoria dos recursos hídricos e demais funções ecológicas. No entanto, o histórico de uso da terra no domínio da Mata Atlântica, um dos mais ameaçados ecossistemas florestais brasileiros, que apresentava em 1998 menos de 9\% de sua cobertura original (Brasil, 1998), mostra que somente no Estado de São Paulo, foram destruídos, entre 1907 e 1934, cerca de $79.500 \mathrm{~km}^{2}$ de floresta nativa, o que corresponde à taxa de $3.000 \mathrm{~km}^{2} / \mathrm{ano}$ (Dean, 1997).

Dados sobre o desmatamento no Estado de São Paulo mostram que entre 1990 e 1995 foram destruídos $674 \mathrm{~km}^{2}$ de Mata Atlântica (Brasil, 1998). Esse desflorestamento e em consequência a degradação dos recursos hídricos, ocasionado pelos diversos usos da terra nos ciclos agro-econômicos que se sucederam na região do Vale do Paraíba paulista determinam a necessidade de recomposição florestal, principalmente das APPs.

O Comitê das bacias Hidrográficas do Rio Paraíba do Sul (CBH-PS) em seu Plano de Bacias (CPTI, 2001) elegeu a bacia do rio Una como prioridade 4, em relação à hierarquização das 128 bacias estudadas, quanto à necessidade de ações imediatas para a recuperação do quadro ambiental. Nesse relatório foram apontadas como ações, que contemplam duas metas, imprescindíveis para a melhoria da qualidade e quantidade de água disponível para o abastecimento de Taubaté e municípios imediatamente à jusante: a primeira visa reduzir a presença de partículas sólidas no rio Una, no ponto de captação para abastecimento de Taubaté, enquanto a segunda meta visa manter a qualidade das águas do rio Una, em seu trecho inferior, nos padrões da Classe 2.

Dados levantados no projeto "Estruturação e Disponibilização do Banco de Dados Ambientais da Bacia do rio Una, Bacia do Rio Paraíba do Sul" (Batista et al., 2005) demonstraram que de um total de $271 \mathrm{Km}^{2}$ de APPs existentes na bacia, $47 \%$ estão em desconformidade de uso, representando uma taxa de 26,6\% em déficit de cobertura florestal em relação à área total da bacia do rio Una. Esse potencial de áreas a serem recuperadas torna-se ainda maior se computados, em adição, a ausência majoritária das áreas de "Reserva Legal", instituída pela Lei Federal n ${ }^{\circ}$ 4.771/65 (Código Florestal), alterada pela Lei Federal $n^{\circ}$ 7.803, de 18 de julho de 1989 e mantida no atual Código aprovado em 2012, e que por si só poderiam representar até $20 \%$ de cada propriedade, que no caso da bacia do rio Una somariam próximo a 9.520 hectares, elevando esse déficit, eventualmente em até $47 \%$ da área total da bacia. 
Nesse contexto, fica evidente a necessidade de esforços de recomposição florestal na bacia do rio Una, o mais importante manancial de Taubaté. Essa bacia abrange $69 \%$ da área do município, que conta com uma população estimada em 278.686 habitantes (IBGE, 2010). Entretanto, é de conhecimento que os custos de recomposição por hectare de reflorestamento com essências nativas são muito altos considerando a economia da maioria das propriedades rurais (IPEF, 2001; Brasil, 2005; Melo, 2005; Barbosa, 2006). Assim, o cenário atual em relação à recomposição florestal, devido à escassez de recursos direcionados para este fim e a grande demanda existente, aponta a necessidade de se desenvolver estudos e métodos de priorização de áreas a serem reflorestadas.

Nesse sentido, o presente trabalho teve como objetivo a identificação de áreas prioritárias e a análise da distribuição espacial dessas áreas por meio do uso de ferramentas computacionais, apoiadas em Sistemas de Informações Geográficas (SIGs) (Eastman, 1995; Câmara et al., 1996) e em técnicas de geoprocessamento aplicadas aos dados pré-existentes e informações de campo (Valente, 2005), cujos resultados podem ser muito importantes para a otimização dos parcos recursos hoje disponíveis para a recuperação florestal.

\section{MATERIAL E MÉTODOS}

\section{1. Área de estudo}

O presente estudo foi realizado na Bacia do rio Una com área de $476 \mathrm{~km}^{2}$ que abrange parte dos municípios de Pindamonhangaba, Redenção da Serra, Taubaté e Tremembé, situados no cone leste do Estado de São Paulo. A área de estudo está delimitada por um retângulo entre as coordenadas UTM dos cantos, inferior esquerdo $E=430.000, N=7.410 .000$ e, superior direito $\mathrm{E}=490.000, \mathrm{~N}=7.460 .000$, Datum horizontal SAD-69 e Meridiano Central $45^{\circ} \mathrm{W}$ (Figura 1).

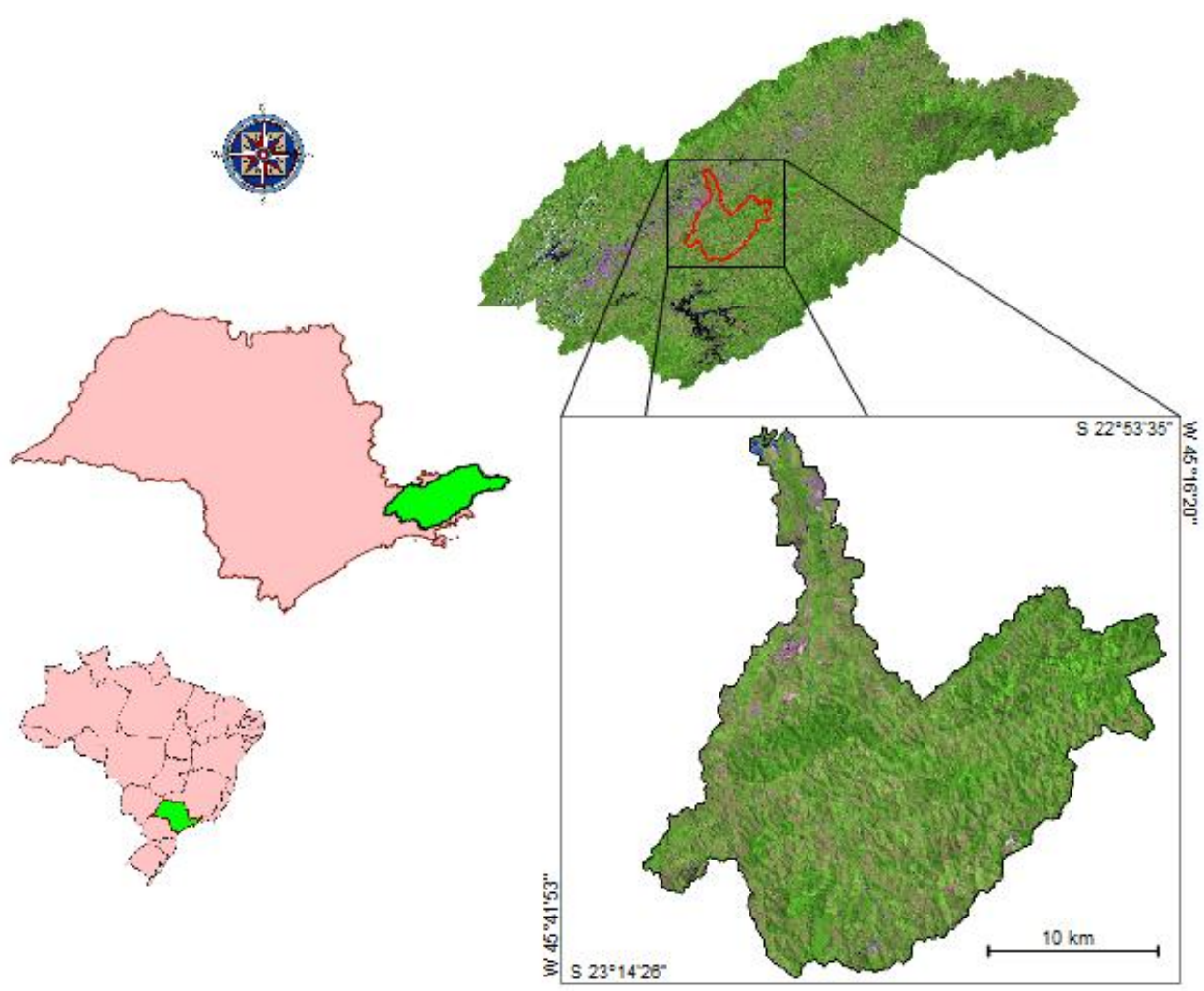

Figura 1. Localização da área de estudo. 


\subsection{Sistemas e técnicas computacionais utilizadas}

O desenvolvimento deste estudo foi baseado na utilização de geotecnologias disponibilizadas em software e linguagem de programação algébrica. O Sistema de Informações Geográficas utilizado foi o SIG completo SPRING - Sistema de Processamento de Informações Georreferenciadas, em sua versão v.4.3.2 (Câmara et al., 1996).

A organização computacional se deu a partir da criação de um banco de dados georreferenciados no SPRING, sobre o qual foram processados os dados de base, os cruzamentos e conversões para compatibilização entre dados matriciais e vetoriais.

A linguagem de programação denominada LEGAL (Linguagem Espacial para Geoprocessamento Algébrico, Cordeiro et al., 1996), foi utilizada para a criação dos programas de transformação de dados temáticos matriciais em dados numéricos matriciais e na discretização de valores numéricos referentes ao intervalo de classificação contínua dos dados no conjunto fuzzy (Klir, 1991), e ainda nos cruzamentos desses dados para a geração dos produtos finais do mapeamento.

As análises de suporte à decisão baseadas em técnicas AHP (Analytical Hierarchy Process, Saaty, 1991) foram processadas utilizando-se um módulo específico do SPRING que possibilita o arranjo das camadas de informação em dupla combinação baseado na "Escala de Valores AHP para Comparação Pareada”.

\subsection{Dados utilizados}

Foram incorporados ao banco de dados georreferenciados, os dados preexistentes produzidos pelo projeto "Estruturação e Disponibilização do Banco de Dados Ambientais da Bacia do rio Una, Bacia do Rio Paraíba do Sul" (Batista et al., 2005), referentes aos temas: Uso da Terra, Malha Viária, Rede de Drenagem, Altimetria, Áreas de Preservação Permanente (APPs), Declividade, Pedologia e Vulnerabilidade a processos erosivos.

\subsection{Mapeamento dos fragmentos florestais}

Com base nos dados de uso da terra oriundos do Projeto Una, foi processado o isolamento da classe "Mata-Capoeira", que corresponde aos fragmentos florestais existentes na bacia. A Figura 2 representa uma amostra de fragmento florestal mapeado como MataCapoeira no Projeto Una, visto no mosaico ortorretificado e sua correspondente foto no campo.
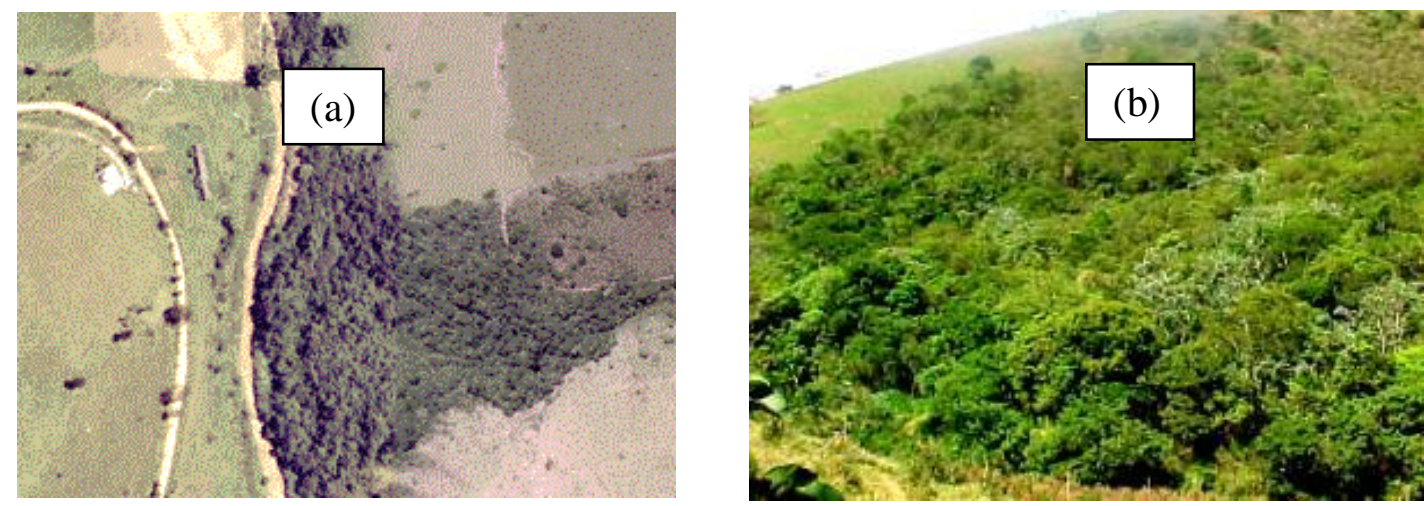

Figura 2. Exemplo da classe Mata-Capoeira a) no Mosaico ortorretificado e b) vista no campo. Essa classe engloba áreas de vegetação natural, pioneira ou secundária em estágio inicial, médio ou avançado de regeneração.

\subsection{Geração do mapa de distância entre fragmentos florestais}

A partir do mapa de fragmentos florestais da Bacia do rio Una foi gerado um mapa de distância no modelo numérico, que corresponde a um mapa matricial no qual as células 
referentes a cada pixel da imagem resultante possuem valores crescentes em metros à medida que se afastam dos fragmentos florestais. $O$ dado numérico resultante desse processo foi agrupado ou fatiado em faixas de $100 \mathrm{~m}$ de largura a partir das bordas dos fragmentos florestais existentes na bacia.

Após a obtenção do mapa de distância entre os fragmentos florestais, foi feita a atribuição de pesos para a normalização dos valores no intervalo $(0,1)$ correspondentes às respectivas faixas de distância entre os fragmentos florestais remanescentes com base no programa escrito em LEGAL.

\subsection{Classes de capacidade de uso e respectivo valor agronômico das terras}

Os dados de Pedologia, Áreas de Preservação Permanente e Declividade, existentes no banco de dados Una (Batista et al., 2005) foram cruzados com base na metodologia desenvolvida pelo Departamento de Agricultura dos Estados Unidos (USDA) e adaptada por Lepsch et al. (1983) para a geração do mapa de classes de capacidade de uso da terra.

Com a informação da classe de capacidade de uso da terra, o valor agronômico pôde ser determinado com base na metodologia utilizada pelo INCRA (2006) que utiliza uma tabela que relaciona a localização e acesso com a capacidade de uso das terras (França, 1983, Tabela 1). No caso em estudo o fator localização e acesso é considerado ótimo, ou seja, a bacia apresenta nos seus diversos cursos, condições de acesso com vias principais asfaltadas, distâncias a vias e centros consumidores próximas e acessos permanentes ao longo do ano. Dessa forma, uma classe de solo associada a uma declividade resulta numa determinada classe de capacidade de uso. Nesse estudo, foram consideradas as classes de capacidade de uso da terra desde a menos restritiva (Classe I) até a mais restritiva (Classe VIII), sem considerar sub-classes relacionadas com a intensidade de restrição descritas por Lepsch et al. (1983). As APPs, por restrição legal, foram agrupadas à classe VIII. Ressalta-se que o mapeamento das APPs envolveu todas as classes de APP, previstas no Código Florestal, 4.771/65 (Brasil, 1965) e Resolução CONAMA 303/2002 (Brasil, 2002). Para cada polígono ou talhão no mapa resultante da classe de capacidade de uso foram atribuídos pesos normalizados no intervalo $(0,1)$ com base na Tabela 1 .

Tabela 1. Fatores de ponderação na obtenção do valor das terras considerando a classe de capacidade de uso e localização.

\begin{tabular}{|c|c|c|c|c|c|c|c|c|c|}
\hline \multirow{2}{*}{\multicolumn{2}{|c|}{$\begin{array}{c}\text { Capacidade } \\
\text { de uso } \\
\text { Localização e } \\
\text { acesso }\end{array}$}} & I & II & III & IV & $\mathbf{V}$ & VI & VII & VIII \\
\hline & & $100 \%$ & $80 \%$ & $61 \%$ & $47 \%$ & $39 \%$ & $29 \%$ & $20 \%$ & $13 \%$ \\
\hline ÓTIMA & $100 \%$ & 1,000 & 0,800 & 0,610 & 0,470 & 0,390 & 0,290 & 0,200 & 0,130 \\
\hline MUITO BOA & $95 \%$ & 0,950 & 0,760 & 0,580 & 0,447 & 0,371 & 0,276 & 0,190 & 0,124 \\
\hline BOA & $90 \%$ & 0,900 & 0,720 & 0,549 & 0,423 & 0,351 & 0,261 & 0,180 & 0,117 \\
\hline REGULAR & $80 \%$ & 0,800 & 0,640 & 0,488 & 0,376 & 0,312 & 0,232 & 0,160 & 0,104 \\
\hline DESFAVORÁ VEL & $75 \%$ & 0,750 & 0,600 & 0,458 & 0,353 & 0,293 & 0,218 & 0,150 & 0,098 \\
\hline MÁ & $70 \%$ & 0,700 & 0,560 & 0,427 & 0,329 & 0,273 & 0,203 & 0,140 & 0,091 \\
\hline
\end{tabular}

Fonte: INCRA (2006).

\subsection{Aplicação do método AHP no processamento do mapa de prioridades}

Após a geração dos produtos base na forma de matrizes numéricas (pesos ponderados e normalizados no intervalo de 0 a 1 correspondentes a cada tema ou fator de peso na determinação de prioridades), os dados foram processados com uso de uma ferramenta de suporte a decisão AHP - Analytical Hierarchy Process, conforme Saaty (1991). O Método baseia-se na "Escala de Valores AHP para Comparação Pareada" (Tabela 2). 
CATElANI, C. S.; BATISTA, G. T.; TARGA, M. S.; DIAS, N. W. Determinação de áreas prioritárias para o restabelecimento da cobertura florestal, apoiada no uso de geotecnologias. Ambi-Agua, Taubaté, v. 7, n. 3, p. 113-126, 2012. (http://dx.doi.org/10.4136/ambi-agua.964)

Tabela 2. Itens da escala de valores AHP para comparação pareada.

\begin{tabular}{c|l}
$\begin{array}{c}\text { Intensidade de } \\
\text { importância }\end{array}$ & \multicolumn{1}{c}{ Definição e Explicação } \\
\hline $\mathbf{1}$ & Importância igual - os dois fatores contribuem igualmente para o objetivo \\
$\mathbf{3}$ & Importância moderada - um fator é ligeiramente mais importante que o outro \\
$\mathbf{5}$ & Importância essencial - um fator é claramente mais importante que o outro \\
$\mathbf{7}$ & $\begin{array}{l}\text { Importância demonstrada - um fator é fortemente favorecido e sua maior relevância foi } \\
\text { demonstrada na prática }\end{array}$ \\
$\mathbf{9}$ & Importância extrema - a evidência que diferencia os fatores é da maior ordem possível \\
& Valores intermediários entre julgamentos - possibilidade de compromissos adicionais \\
\hline
\end{tabular}

O mapa de prioridade para recomposição florestal da Bacia do rio Una numérico e normalizado foi então processado por técnica de fatiamento no módulo de processamento do modelo numérico do SPRING, dando origem a um mapa temático contendo a espacialização das classes de prioridade para recomposição florestal, divididas em:

- Prioridade Extrema, atribuída aos valores normalizados entre 0.9 e 1.0;

- Prioridade Alta atribuída aos valores normalizados entre 0.7 e 0.9 ;

- Prioridade Média atribuída aos valores normalizados entre 0.4 e 0.7 e,

- Prioridade Baixa atribuída aos valores normalizados entre 0 e 0.4.

O limite inferior de cada intervalo é incluído na classe, enquanto o superior é excluído, exceto para a classe $(0,9$ a 1,0$)$.

\section{RESULTADOS E DISCUSSÃO}

\subsection{Mapa fragmentos florestais e de classes de capacidade de uso da terra}

O Mapa de fragmentos e de distância entre fragmentos florestais nativos da bacia do rio Una, gerado em um modelo numérico, trata-se de um mapa matricial, no qual as células referentes a cada pixel da imagem resultante possuem valores crescentes em metros da distância entre fragmentos, como resultado do fatiamento em faixas preestabelecidas a cada $100 \mathrm{~m}$, à medida em que se afastam dos fragmentos florestais, representados pela classe MataCapoeira, originária do mapa de uso do solo (Batista et al., 2005). O mapa resultante demonstra um alto grau de fracionamento e dispersão dos fragmentos florestais remanescentes. A Tabela 3 mostra a área e a percentagem de ocorrência dos remanescentes.

Tabela 3. Resultado da classificação do mapa de distância entre fragmentos florestais nativos da bacia do rio Una.

\begin{tabular}{c|ccc}
\hline Classe & Faixa de Distância & Área (ha) & Área (\%) \\
\hline Mata-Capoeira & 0 & 10083,3 & 21,18 \\
$0-100$ & $0-100$ & 14973,0 & 31,46 \\
$100-200$ & $100-200$ & 10149,4 & 21,32 \\
$200-300$ & $200-300$ & 5924,0 & 12,45 \\
$300-400$ & $300-400$ & 3207,8 & 6,74 \\
$400-500$ & $400-500$ & 1669,7 & 3,51 \\
$500-600$ & $500-600$ & 799,2 & 1,68 \\
$600-700$ & $600-700$ & 400,5 & 0,84 \\
$700-800$ & $700-800$ & 211,6 & 0,44 \\
$800-900$ & $800-900$ & 121,9 & 0,26 \\
900 ou + & 900 ou + & 59,7 & 0,13 \\
\hline \multicolumn{4}{c}{ Total } \\
\hline
\end{tabular}


Os resultados do mapa de distância entre fragmentos da bacia (Tabela 3) demonstraram que cerca de $53 \%$ da área total situa-se a uma distância inferior a $200 \mathrm{~m}$ (faixas de $0-100 \mathrm{~m}$ e $100-200 \mathrm{~m}$ ) em relação ao fragmento florestal nativo mais próximo, o que facilita a conexão entre fragmentos e dessa forma, pode-se indicar a adoção de métodos de restabelecimento baseados em nucleação (Reis et al., 2003). Esse mapa de distância permite visualizar possíveis rotas de ligação de corredores ecológicos e possíveis uniões entre fragmentos e ainda, levando-se em consideração a rede hidrográfica, permite também, observar a configuração da cobertura florestal do conjunto ripário (Lima e Zakia, 2000).

\subsection{Mapa de classes de capacidade de uso da terra e respectivo índice de valor agronômico da terra na bacia do rio una}

Os cruzamentos dos mapas de pedologia, APPs e declividade permitiram a geração do mapa de classes de capacidade de uso do solo (Figura 3). Nesse resultado de considerável complexidade técnica para mensuração (Lepsh et al., 1983) reside uma das mais controversas questões para a indicação de áreas particulares em que devam ser restauradas ou restabelecidas as florestas originais, visto que a adesão de proprietários rurais e a destinação de áreas adequadas a esse fim esbarram no tipo de uso atual dado pelo proprietário, com considerável índice de desistência de projetos de recomposição florestal (Ferretti, 2000). O Mapa de classes de capacidade de uso da terra e respectivo índice de valor agronômico das terras da bacia do rio Una (Figura 3), elaborado com base no sistema adaptado por Lepsch et al. (1983) considera quatro categorias: grupos, classes, subclasses e unidade de restrição à capacidade de uso, definidas em função das características dos solos, declividade e fatores limitantes ao uso da terra. As análises, nesse estudo, se restringiram às classes que são representadas por algarismos romanos (I a VIII), identificadas pelo grau de limitação da capacidade de uso agrícola da terra (Tabela 4).

$\mathrm{Na}$ execução dos processos que resultaram no Mapa de classes de capacidade de uso da terra e respectivo índice de valor agronômico das terras da Bacia do rio Una, em adição aos dados de entrada correspondente ao mapa de solos e de declividade da bacia, foram integrados nesse estudo, os dados do mapa de APPs, que por si só representam restrição legal ao uso da terra, com consequente classificação de todas APPs existentes na bacia como Classe VIII de capacidade de uso da terra.

Tabela 4. Resultado da classificação de capacidade de uso da terra e respectivo índice de valor agronômico das terras, expressos em porcentagem e hectares.

\begin{tabular}{l|crr}
\hline $\begin{array}{l}\text { Classe de } \\
\text { capacidade de } \\
\text { uso do solo }\end{array}$ & $\begin{array}{c}\text { Índice de valor da } \\
\text { terra (INCRA) }\end{array}$ & Área (ha) & Área (\%) \\
\hline Classe_I & 100 & 261 & 0,6 \\
Classe_II & 80 & 6 & 0,0 \\
Classe_III & 61 & 4783 & 10,1 \\
Classe_IV & 47 & 2671 & 5,6 \\
Classe_V & 39 & 0 & 0,0 \\
Classe_VI & 29 & 7316 & 15,4 \\
Classe_VII & 20 & 5805 & 12,2 \\
Classe_VIII & 13 & 26758 & 56,2 \\
\hline Total & & $\mathbf{4 7 6 0 0}$ & $\mathbf{1 0 0 , 0}$ \\
\hline
\end{tabular}


Conforme mostrado na Tabela 4 a Classe VIII ocupa 56,2\% do total da bacia. Mais da metade da área total da bacia possui restrições ao uso da terra, que de acordo com Mendonça et al. (2006), só poderia ser utilizada como abrigo da flora e fauna silvestres, como ambiente para atividades de recreação e educação ambiental ou para fins de armazenamento de água.

No processamento do mapa de classe de capacidade de uso e valor agronômico da terra, por meio de um programa escrito em LEGAL, foram atribuídos pesos normalizados no intervalo $(0,1)$, o que gerou o mapa correspondente no modelo numérico. Observa-se claramente o grau de prioridade indicado pela Classe VIII de capacidade de uso da terra, principalmente pela sua característica restritiva herdada do mapa de APPs do Projeto Una (Dias et al., 2008).

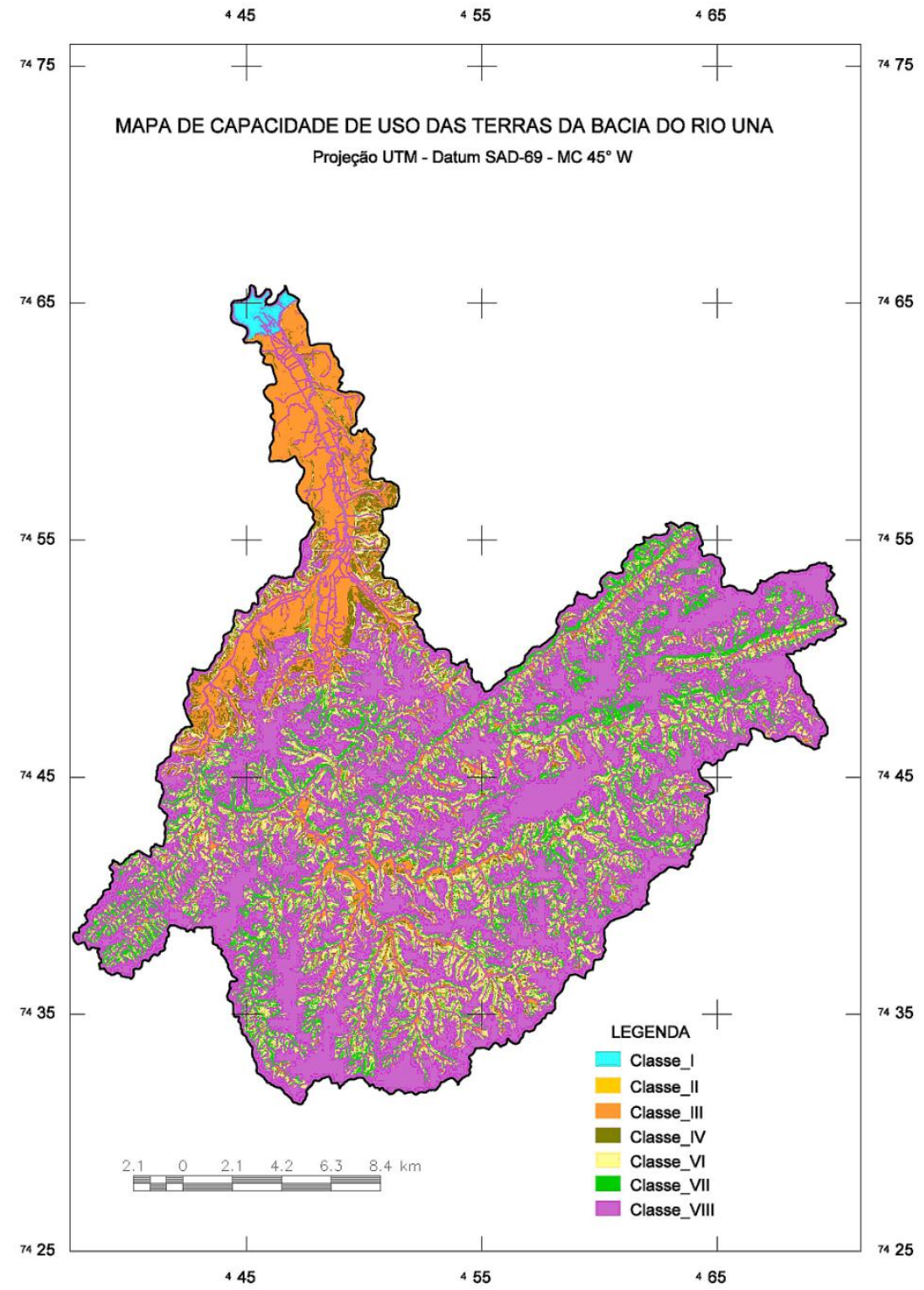

Figura 3. Mapa de classes de capacidade de uso das terras da bacia do rio Una.

O cruzamento do mapa de uso do solo com o mapa de classes de capacidade de uso da terra demonstrou uma intersecção de 6.927 ha da classe Mata-Capoeira com a Classe VIII de capacidade de uso da terra, ou seja, apenas $25,9 \%$ da Classe VIII na bacia apresenta 
conformidade de uso. Tal fato demonstra que o uso predominante está em desacordo com a vocação natural de capacidade de uso da terra (Tabela 5).

Tabela 5. Resultado do cruzamento do mapa de classes de capacidade de uso da terra e respectivo índice de valor agronômico das terras X mapa de uso do solo, em hectares.

\begin{tabular}{l|rrrrrrr}
\multicolumn{1}{c}{ Classes de capacidade } & \multicolumn{1}{c}{\begin{tabular}{c} 
I \\
\cline { 2 - 8 } \multicolumn{1}{c}{ Uso uso do solo }
\end{tabular}} & \multicolumn{1}{c}{ I } & III & IV & VI & VII & VIII \\
\hline Mata-Capoeira & 30,2 & 0,1 & 357,1 & 203,8 & 902,3 & 1662,5 & $\mathbf{6 9 2 7 , 1}$ \\
Agricultura & 41,1 & 0,0 & 169,6 & 66,9 & 97,0 & 19,4 & 210,8 \\
Pasto & 54,1 & 0,4 & 3398,4 & 2038,2 & 5260,7 & 3223,8 & 14925,3 \\
Reflorestamento & 0,6 & 0,0 & 64,4 & 78,2 & 409,6 & 363,5 & 1610,4 \\
Solo Exposto & 0,0 & 0,0 & 94,0 & 56,8 & 65,7 & 14,8 & 136,2 \\
Área Degradada & 0,0 & 0,0 & 0,8 & 6,4 & 4,8 & 2,6 & 21,6 \\
Área Urbanizada & 0,5 & 0,0 & 427,4 & 59,2 & 19,3 & 0,7 & 116,4 \\
Pasto Sujo & 0,0 & 0,0 & 117,9 & 95,7 & 331,1 & 378,0 & 1962,3 \\
Pasto Degradado & 6,6 & 0,0 & 54,4 & 45,1 & 173,1 & 115,0 & 647,7 \\
Corpos d'água & 94,2 & 5,6 & 75,3 & 7,6 & 23,0 & 1,3 & 22,9 \\
Reflorestamento cortado & 0,0 & 0,0 & 0,9 & 3,3 & 18,9 & 17,8 & 144,8 \\
Área Minerada & 31,4 & 0,2 & 12,1 & 5,9 & 6,1 & 3,8 & 32,4 \\
\hline \multicolumn{1}{c}{ Total } & 260,8 & 6,3 & 4782,8 & 2671,3 & 73116,4 & 5804,6 & $\mathbf{2 6 7 5 7 , 8}$ \\
\hline
\end{tabular}

\subsection{Mapeamento das classes de prioridade para recomposição florestal da bacia do rio} Una

Os dados de base relativos à cada camada de informação, pré-processados por média ponderada e normalizados no intervalo ( 0 a 1 ) também denominados conjunto fuzzy, foram submetidos à comparação pareada no módulo de suporte à decisão AHP do SPRING v. 4.3.2, o que retornou um índice de consistência de 0.042 (Figura 4), considerado consistente, uma vez que valores inferiores a 0.1 para a execução do módulo de decisão em técnica AHP são recomendados (Valente, 2005). Com base no programa em LEGAL, utilizando-se as camadas de informação, previamente trabalhadas obteve-se o mapa de prioridade para recomposição florestal da Bacia do rio Una numérico normalizado.

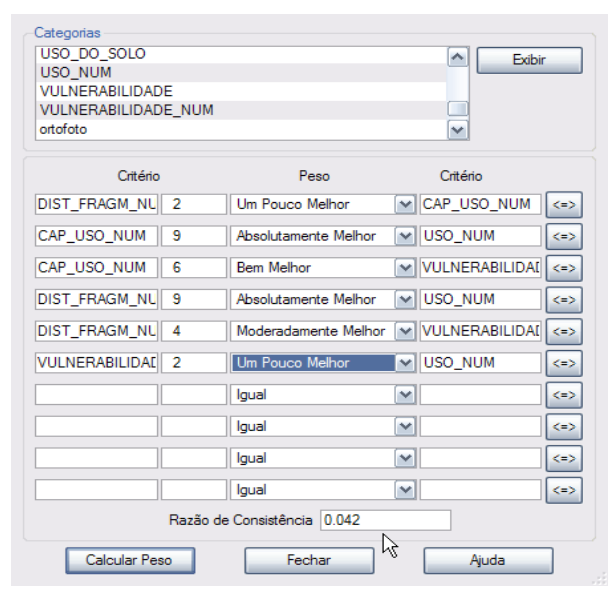

Figura 4. Captura de tela do módulo de tomada de decisão AHP do SPRING, com os respectivos pares e a respectiva razão de consistência. 


\subsection{Mapa Temático de prioridade para o restabelecimento da cobertura florestal nativa da bacia do rio Una}

O mapa de prioridade para o restabelecimento da cobertura florestal nativa da bacia do rio Una numérico e normalizado, após processado por técnica de fatiamento no módulo do modelo numérico do SPRING v.4.3.2, resultou no mapa temático que contém a espacialização das classes de prioridade para recomposição florestal.

Os resultados do mapa temático de prioridade para o restabelecimento da cobertura florestal nativa da Bacia do rio Una demonstram numa avaliação visual que a descontinuidade das classes no modelo numérico permite uma representação não condicionada ao verdadeiro ou falso e não produz polígonos com limites rígidos que se observa quando se trabalha com cruzamentos booleanos. Burrough e McDonnell (1998) já alertavam que os principais problemas relacionados às operações booleanas são os limiares nítidos e rígidos, que nem sempre representam os fenômenos naturais corretamente, visto que na natureza os fenômenos não são representados por limites estáticos ou rígidos.

A fusão do mapa de fragmentos florestais no mapa temático de prioridade se faz necessária uma vez que nos locais onde existe floresta nativa, a prioridade de recomposição deve ser nula.

Os resultados obtidos da inserção dos fragmentos florestais na camada final correspondente ao mapa temático final de prioridade para o restabelecimento da cobertura florestal nativa da bacia do rio Una estão representados na Figura 5 enquanto os dados tabulares referentes às respectivas classes de prioridade expressos em hectares e porcentagem são apresentados na Tabela 6.

Tabela 6. Área e percentagem de cada classe de prioridade para o restabelecimento da cobertura florestal da bacia do rio Una.

\begin{tabular}{|l|cc}
\hline \multicolumn{1}{|c|}{ Classe } & Área (ha) & Área (\%) \\
\hline Mata_Capoeira & 10082 & 21,2 \\
Prioridade baixa & 253 & 0,5 \\
Prioridade média & 6346 & 13,3 \\
Prioridade alta & 18388 & 38,6 \\
Prioridade extrema & 12663 & 26,6 \\
\hline \multicolumn{1}{|c|}{ Total } & $\mathbf{4 7 6 0 0}$ & $\mathbf{1 0 0 , 0}$ \\
\hline
\end{tabular}

Nota: As cores na tabela correspondem às cores do mapa na Figura 5.

Pelos resultados finais do mapeamento das classes de prioridade para o restabelecimento da cobertura florestal da Bacia do rio Una (Tabela 6) demonstra-se que a qualidade ambiental da bacia está ruim, pois uma área correspondente a 26,6\% da área total da bacia encontra-se em situação de "Prioridade Extrema" para a recomposição florestal.

O cruzamento do mapa de prioridade para recuperação com o mapa de APPS (Dias et al., 2008) revelou que $72,7 \%$ das APPs da bacia encontram-se sob prioridades Alta (7473 ha ou $27,8 \%$ ) e Extrema (12051 ha ou 44,9\%) para o restabelecimento da cobertura vegetal nativa (Tabela 7), o que nos leva a duas novas informações relevantes, somente $27,4 \%$ das APPs encontram-se com cobertura vegetal apropriada, e o restante sob condição predominante entre alta e extrema prioridade para recomposição da cobertura florestal nativa. 
CATElANI, C. S.; BATISTA, G. T.; TARGA, M. S.; DIAS, N. W. Determinação de áreas prioritárias para o restabelecimento da cobertura florestal, apoiada no uso de geotecnologias. Ambi-Agua, Taubaté, v. 7, n. 3, p. 113-126, 2012. (http://dx.doi.org/10.4136/ambi-agua.964)

Tabela 7. Resultado do cruzamento do mapa de prioridades para o restabelecimento da cobertura vegetal nativa $\mathrm{X}$ mapa de APPs, em hectares.

\begin{tabular}{l|cccccc}
\hline \multicolumn{1}{c|}{ Prioridades } & Mata Capoeira & Baixa & Média & Alta & Extrema & Total (APPs) \\
\hline APP Lago Lagoa Represa & 4 & 0 & 5 & 50 & 49 & $\mathbf{1 0 8}$ \\
APP Nascente & 487 & 0 & 22 & 558 & 787 & $\mathbf{1 8 5 4}$ \\
APP Topo de Morro & 4058 & 0 & 202 & 4437 & 7907 & $\mathbf{1 6 6 0 3}$ \\
APP Rios ate 10m & 2268 & 0 & 154 & 2386 & 3208 & $\mathbf{8 0 1 5}$ \\
APP Rios entre 10-50 & 109 & 0 & 0 & 42 & 101 & $\mathbf{2 5 2}$ \\
APP Reservatório & 6 & 0 & 5 & 1 & 0 & $\mathbf{1 2}$ \\
APP Cavas & 1 & 0 & 26 & 0 & 0 & $\mathbf{2 8}$ \\
\hline Total (Prioridades) & $\mathbf{6 9 3 3}$ & $\mathbf{0}$ & $\mathbf{4 1 4}$ & $\mathbf{7 4 7 3}$ & $\mathbf{1 2 0 5 1}$ & $\mathbf{2 6 8 7 1}$ \\
\hline
\end{tabular}

Observa-se também que dos 12663 ha de "Prioridade Extrema", 12051 ha situam-se em APPs, o que corresponde a uma intersecção equivalente a 95,2\%, e demonstra a influência das APPs na priorização de áreas para recomposição florestal.

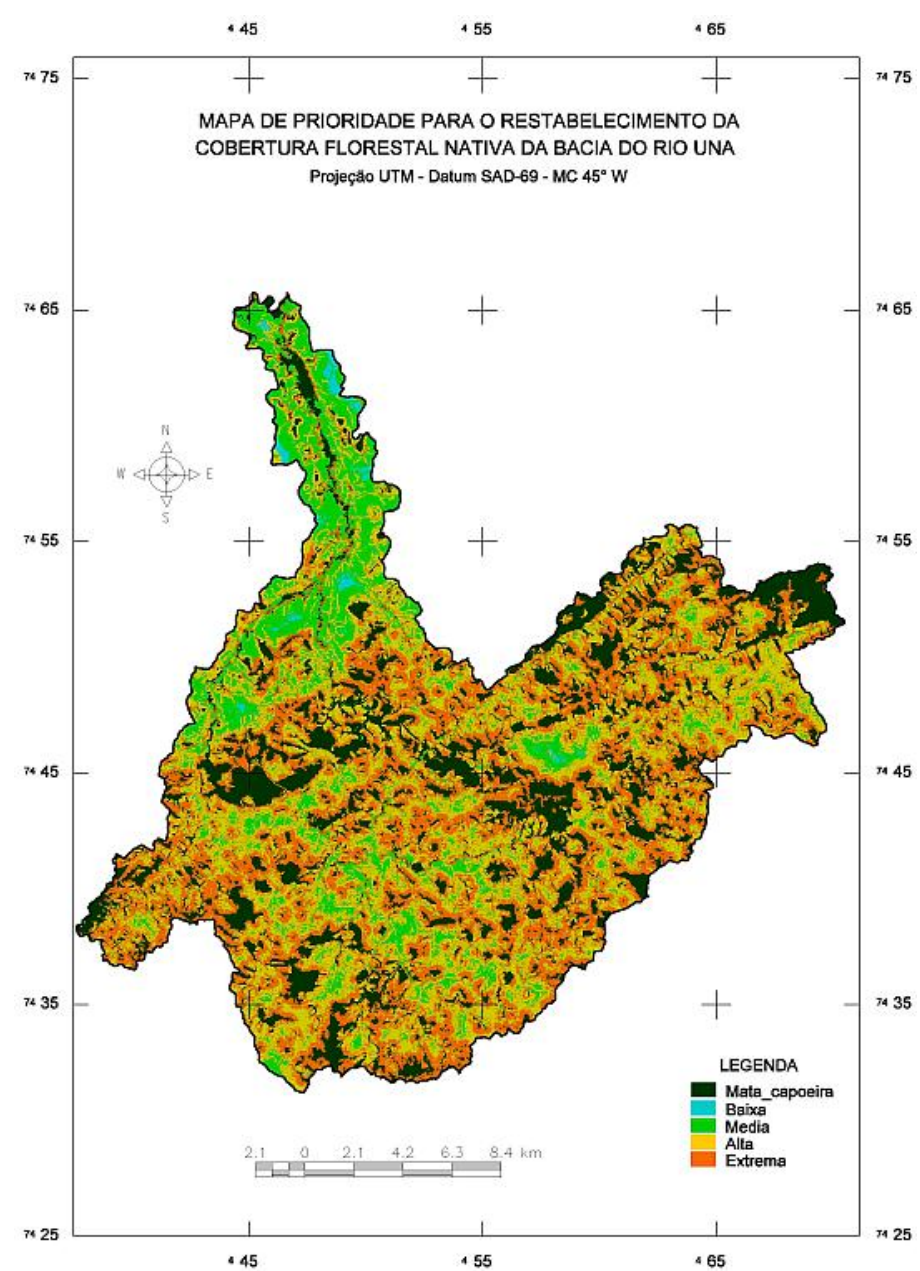

Figura 5. Mapa temático final de prioridade para o restabelecimento da cobertura florestal nativa da bacia do rio Una. 
Santos (1991) classificou os estados alterados da paisagem como rugosidades que expressam o resultado de um comportamento social, nesse sentido, o predomínio absoluto das classes de Prioridade Alta e Extrema, que juntas somam 65,3\% da área da bacia, demonstra em números a gravidade do legado de séculos seguidos de exploração dos recursos naturais, especialmente dos solos, dos recursos hídricos e da flora na região, legado que já foi descrito por Dean (1997).

Como finalidade prática, os resultados desse trabalho podem subsidiar a tomada de decisão na alocação de recursos destinados ao restabelecimento da cobertura florestal nativa da bacia do rio Una, e assim servir como elemento de remediação do quadro de degradação dos recursos hídricos da bacia, apontados no Relatório de Situação da Bacia Hidrográfica do Rio Paraíba do Sul (CPTI, 2001).

\section{CONCLUSÃO}

O presente trabalho permitiu formular algumas conclusões a respeito da priorização de áreas para o restabelecimento da cobertura florestal nativa da bacia do rio Una, que seguem:

A prioridade técnica para a recomposição florestal dessa bacia apresentou uma grande intersecção de área associada às Áreas de Preservação Permanente (APPs), o que ratifica o conceito dessas APPs;

A bacia hidrográfica do rio Una, em Taubaté, SP, apresenta uma situação preocupante, com $26,6 \%$ de sua área detectada como de "prioridade extrema" para o restabelecimento da cobertura florestal nativa;

O mapeamento da prioridade de recuperação da bacia do rio Una em níveis numéricos espacializados permite uma otimização na implantação de projetos de restabelecimento de cobertura florestal nativa nessa bacia, cuja metodologia pode ser replicada para outras regiões.

\section{REFERÊNCIAS}

BARBOSA, L. M. (Coord.). Manual para recuperação de áreas degradadas em matas ciliares do estado de São Paulo. São Paulo: Instituto de Botânica, 2006. 147p. Disponível em: <http://files.pereiraim.webnode.com.br/2000000424f33f502df/Manual\%20RMC-SP.pdf\#page=132>. Acesso em: nov. 2012.

BATISTA, G. T.; TARGA, M. S.; FIDALGO, E. C. C. Banco de dados ambientais da bacia do rio Una, bacia do Rio Paraíba do Sul. Taubaté, 2005. 16p. Disponível em: <http://www.agro.unitau.br:8080/dspace/bitstream/2315/51/1/Projeto_Una_IBICT.pdf>. Acesso em: 26 nov. 2012.

BRASIL. Conselho Nacional do Meio Ambiente - CONAMA. Resolução No 303 de 20 de março de 2002. Dispõe sobre parâmetros, definições e limites de Áreas de Preservação Permanente. Disponível em: <http://www.mma.gov.br/port/conama/res/res02/ res30302.html>. Acesso em: 18 dez. 2012.

Fundo Nacional do Meio Ambiente - FNMA. Edital FNMA No 2/2005. Chamada I - recuperação e proteção de nascentes e áreas que margeiam corpos d'água, adequação ambiental e avaliação qualitativa e quantitativa das águas. Disponível em: <http://www.meioambiente.gov.br/port/fnma/capa/index.html>. Acesso em: 24 ago. 2005.

Lei № 4.771, de 15 de setembro de 1965. Institui o novo Código Florestal. Diário Oficial [da] República Federativa do Brasil, Poder Executivo, Brasília, DF, 16 set. 1995. 
Lei $N^{0}$ 12.651, de 25 de maio de 2012. Dispõe sobre a proteção da vegetação nativa; altera as Leis $\mathrm{n}^{\mathrm{os}}$ 6.938, de 31 de agosto de 1981, 9.393, de 19 de dezembro de 1996, e 11.428, de 22 de dezembro de 2006; revoga as Leis $\mathrm{n}^{\text {os }} 4.771$, de 15 de setembro de 1965, e 7.754, de 14 de abril de 1989, e a Medida Provisória no 2.166-67, de 24 de agosto de 2001; e dá outras providências. Diário Oficial [da] República Federativa do Brasil, Poder Executivo, Brasília, DF, 28 maio 2012.

Ministério do Meio Ambiente. Primeiro relatório nacional para a convenção sobre diversidade biológica - Brasil. Brasília, DF, 1998.

BURROUGH, P. A.; MCDONNELL, R. A. Principles of Geographical Information Systems. Oxford: Oxford University Press, 1998. 333 p.

CÂMARA G.; SOUZA R. C. M.; FREITAS U. M.; GARRIDO J. SPRING: integrating remote sensing and GIS by object-oriented data modelling. Computers \& Graphics, v. 20, n. 3, p. 395-403, 1996. http://dx.doi.org/10.1016/0097-8493(96)00008-8

CORDEIRO, J. P.; AMARAL, S.; FREITAS, U. M.; CÂMARA NETO, G. Álgebra de geocampos e suas aplicações. In: SIMPÓSIO BRASILEIRO DE SENSORIAMENTO REMOTO, 8., 14-19 abr. 1996, Salvador. Anais... São José dos Campos: INPE, 2006. p. 355-361. 1 CD-ROM.

COOPERATIVA DE SERVIÇOS, PESQUISAS TECNOLÓGICAS E INDUSTRIAIS CPTI. Plano das bacias hidrográficas do rio Paraíba do Sul 2000-2003. São Paulo, 2001. 1 CD-ROM.

DEAN, W. A ferro e fogo: a história da devastação da mata atlântica brasileira. São Paulo: Companhia das Letras, 1997.

DIAS, N. W.; BATISTA, G. T.; TARGA, M. S. Water use fund applied to land cover characterization and water quality analysis to support hydrographic basin committee decisions in Brazil. In: INTERNATIONAL WATER CONGRESS AND EXHIBITION, 2008, Viena. Proceedings... Viena: IWA, 2008. Vol. 1. p. 1-8. Disponível em: <http://www.agro.unitau.br:8080/dspace/bitstream/2315/144/1/Artigo_WWC_Una_ Ciencias_Agrarias.pdf $>$. Acesso em: 22 nov. 2012.

EASTMAN, J. R. IDRISI for Windows: user's guide. Massachusetts: Clark University, 1995. 367p.

FERRETTI, A. C. O fomento florestal da CESP/Porto Primavera com propriedades da região de Assis - SP. 2000. 156 f. Dissertação (Mestrado) - Escola Superior de Agricultura “Luiz de Queiroz", Universidade de São Paulo, Piracicaba, 2000.

FRANÇA, G. V. Estudo agrotécnico e avaliações das terras da Fazenda São Sebastião, município de santa Cruz das Palmeiras - SP: levantamento de solos, capacidade de uso e valor relativo das terras. Piracicaba: ESALQ-USP, 1983.

INSTITUTO BRASILEIRO DE GEOGRAFIA E ESTATÍSTICA - IBGE. Cidades@: censo 2010. Disponível em: <http://www.ibge.gov.br/cidadesat/topwindow.htm?1>. Acesso em: 21 nov. 2012.

INSTITUTO DE PESQUISAS E ESTUDOS FLORESTAIS - IPEF. Projeto Corumbataí. Conservação dos recursos hídricos e da cobertura florestal na Bacia do Rio Corumbataí. Piracicaba: IPEF, 2001. 118 p. Relatório do projeto.

INSTITUTO NACIONAL DE COLONIZAÇÃO E REFORMA AGRÁRIA - INCRA. (Brasil). Manual de obtenção de terras e perícia judicial. Brasília, DF, 2006. 123p. 
KLIR, G. J. Generalized information theory. Fuzzy Sets and Systems, v. 40, n. 1, p. 127142, 1991. http://dx.doi.org/10.1016/0165-0114(91)90049-V

LEPSCH, I. F.; BELLINAZZI JR., R.; BERTOLINI, D.; ESPÍNDOLA, C. R. Manual para levantamento utilitário do meio físico e classificação de terras no sistema de capacidade de uso: $4^{\mathrm{a}}$ aproximação. Campinas: SBCS, 1983. 175p.

LIMA, W. P.; ZAKIA M. J. B. Hidrologia de matas ciliares. In: RODRIGUES, R. R.; LEITÃO FILHO, H. F. (Eds.). Matas ciliares: conservação e recuperação. Piracicaba: EDUSP/FAPESP, 2000. p. 33-44.

MENDONCA, I. F. C.; LOMBARDI NETO, F.; VIÉGAS, R. A. Classificação da capacidade de uso das terras da Microbacia do Riacho Una, Sapé, PB. Revista Brasileira de Engenharia Agrícola e Ambiental, v. 10, n. 4, p. 888-895, 2006. http://dx.doi.org/10.1590/S1415-43662006000400016

MELO, A. C. G. de. A legislação como suporte a programas de recuperação florestal no estado de São Paulo. Florestar Estatístico, v. 8, p. 9-15, 2005.

REIS, A.; BECHARA, F. C.; ESPÍNDOLA, M. B.; VIEIRA, N. K.; SOUZA, L. L. Restauração de áreas degradadas: a nucleação como base para incrementar os processos sucessionais. Natureza \& Conservação, v. 1, n. 1, p.28-36, 2003.

SAATY, T. L. Método de análise hierárquica. São Paulo: McGraw-Hill, 1991.

SANTOS, M. Pensando o espaço do homem. 3. ed. São Paulo: Hucitec, 1991.

VALENTE, R. O. A. Definição de áreas prioritárias para conservação e preservação florestal por meio da abordagem multicriterial em ambiente SIG. 2005. $121 \mathrm{f}$. Tese (Doutorado em Recursos Florestais) - Escola Superior de Agricultura Luiz de Queiroz, Universidade de São Paulo, Piracicaba, 2005. 